\title{
Inheritance of behavioural differences betw een two interfertile, sympatric species, Drosophila silvestris and D. heteroneura
}

\author{
CHRISTINE R. B. BOAKE*, DONALD K. PRICE $\dagger$ \& DEBRA K. ANDREADIS \\ Department of Ecology and Evolutionary Biology, The University of Tennessee, Knoxville, TN 37996, U.S.A.
}

\begin{abstract}
The Hawaiian fly species, Drosophila silvestris and D. heteroneura, are sympatric and interfertile but show strong behavioural isolation and major differences in male aggressive behaviour and the associated morphology. As a first step in elucidating the genetic control of the differences between these species, we examined the mating and aggressive behaviour of their reciprocal $F_{1}$ hybrids. The latency to the first wing vibration and the latency to copulate did not differ significantly between the parental species. However, D. heteroneura females had a very low tendency to copulate with $D$. silvestris males, rarely mating during the observation period. The duration of copulation also differed significantly: same-species pairs of $D$. silvestris had copulations that lasted about $50 \%$ longer than those of same-species pairs of D. heteroneura. The hybrids were intermediate between the parental species for both the tendency to copulate with $D$. silvestris males and the duration of copulation, suggesting codominance or polygenic inheritance for those traits. The aggression traits that we scored were the leg posture and wing extension during early aggression, and the leg posture and head position during escalated aggression. The parental species showed clear differences for each of these traits. The $F_{1}$ hybrids resembled one parent or the other, without showing intermediate values, suggesting single-gene dominance or threshold expression of many genes for those traits. None of the courtship or aggressive traits showed X-chromosomal effects, although the head shape of hybrids is influenced by genes on the $\mathrm{X}$ chromosome. It is difficult to reconcile the patterns of inheritance of aggressive behaviour and the lack of an X-chromosomal effect with the hypothesis that these traits are influenced by a coadapted gene complex.
\end{abstract}

Keywords: aggression, behavioural isolation, courtship, Hawaiian Drosophila, hybrids, speciation.

\section{Introduction}

Behavioural reproductive isolation appears to represent an early stage in the process of divergence of sympatric species (Coyne \& Orr, 1989). It also may be a major component of the process of speciation in cases in which the species show little ecological divergence (Kaneshiro \& Boake, 1987). Behavioural isolation has received far less attention than other forms of isolation such as hybrid sterility, despite its potential for elucidating the process of speciation (Coyne, 1992; Turner \& Burrows, 1995). Two important contemporary issues in the study of

*Correspondence. E-mail: cboake@utk.edu

$\dagger$ Present address: Department of Biology, University of Hawaii at Hilo, Hilo, HI 96720-4091, U.S.A. E-mail: donaldp@hawaii.edu behavioural isolation are the nature of the genetic changes that accompany speciation (Barton \& Charlesworth, 1984; Carson \& Templeton, 1984) and the role of sexual selection in speciation (Kaneshiro \& Boake, 1987; Kaneshiro, 1989).

The genetic issues in speciation focus on whether speciation is the result of the accumulation of small changes at many loci (Charlesworth et al., 1982) or the result of a genetic transilience or other major genetic reorganization (Carson \& Templeton, 1984). Because reproductive isolation is the core of speciation, tests of genetic hypotheses need to be conducted on the traits that are most likely to be responsible for reproductive isolation. The Hawaiian Drosophila have played a central role in the development of hypotheses that relate genetic reorganization to speciation (Carson \& Templeton, 1984), 
making them critical for testing these hypotheses. In this paper we examine the inheritance of several sexual behaviours that may be important in the process of speciation for two Hawaiian Drosophila species.

The process of speciation through sexual selection could occur in the absence of substantial adaptive divergence (Lande, 1981a). This kind of speciation may have happened with the large flies Drosophila silvestris and D. heteroneura (Kaneshiro, 1976; Carson, 1982), which are endemic to the same forests on the Island of Hawaii and ecologically very similar. By the standards of the genus, they have diverged recently, being no more than $4 \times 10^{5}$ yr old and having a Nei's similarity coefficient of 0.94 (Carson, 1982). They show no postzygotic isolation (Craddock, 1974; Val, 1977; Ahearn \& Templeton, 1989) but do show prezygotic behavioural isolation, with the pairing of $D$. heteroneura females with $D$. silvestris males being very unlikely to result in copulation (Craddock, 1974; Val, 1977; Price \& Boake, 1995; Fraser \& Boake, 1997). Thus the main barrier to gene flow is behavioural, making this pair ideal for examining the genetic nature of behavioural isolation.

This paper is one part of a larger study of the nature and control of behavioural isolation between $D$. silvestris and D. heteroneura. We have reported that the $F_{1}$ hybrids are not at a disadvantage in aggression and in courtship (Price \& Boake, 1995). Here we address the question of the nature of the inheritance of behavioural differences. In this stage of the project, we made reciprocal crosses between Drosophila silvestris and D. heteroneura and examined behavioural traits in their $F_{1}$ hybrids. We found that the pattern of inheritance in the $F_{1}$ differed substantially for courtship and aggressive behaviour, with simple dominance being adequate to explain differences in aggressive behaviour, whereas the courtship traits were intermediate in the hybrids and could be under polygenic control.

\section{Materials and methods}

The flies

Both D. silvestris and D. heteroneura are found in the same forests, between $1000 \mathrm{~m}$ and $1300 \mathrm{~m}$ altitude on the wetter slopes of the volcanoes on the Island of Hawaii (D. silvestris can be found as high as $1700 \mathrm{~m}$ but $D$. heteroneura occupies lower altitudes; Carson, 1982). The two species have the same general ecological requirements, sometimes even being reared out of the same piece of rotten host material (Conant, 1978; Carson et al., 1989). The species have very similar courtship behaviour (Spieth, 1978; Hoikkala \& Welbergen, 1995) although they show asymmetric behavioural isolation (Kaneshiro, 1976; Price \& Boake, 1995; Fraser \& Boake, 1997): D. silvestris females and D. heteroneura males mate readily, but the reciprocal pairing rarely results in copulation.

Males of the two species are markedly divergent in their aggressive behaviour (Spieth, 1981). Male $D$. silvestris fight by approaching each other with their legs extended (a stilt-walk), and then push and shove each other with one or both wings extended laterally; they attempt to push each other over backwards. Males of $D$. heteroneura fight by crouching close to the substrate and approaching each other with both wings extended laterally, until their heads touch somewhat in the fashion of mountain sheep; they shove until one male leaves. The head shapes of males from these species reflect the differences in fighting style: $D$. silvestris heads are characteristic of the genus, being round, but D. heteroneura males look hammer-headed. Females show some differences in head shape, but the eyestalks of female $D$. heteroneura are not as pronounced as those of the males. The species differences in head shape show a substantial influence of the $\mathrm{X}$ chromosome, as well as numerous autosomal influences (Templeton, 1977; Val, 1977; Lande, 1981b).

\section{Rearing}

HawaiianDrosophila ofthisgrouparerearedat $18^{\circ} \mathrm{C}, 70 \%$ relative humidity, on a $13 \mathrm{~h}: 11 \mathrm{~h}$ light: dark cycle, which emulates the cycle in the cloud forests in which they live. A generation takes about 3 months in the laboratory. Larvae are fed with a modified cornmeal-molasses food, they pupate in damp sand, and adults are fed with a yeastless Wheeler-Clayton medium (Carson, 1987).

Drosophila silvestris was represented by two isofemale lines, called U26B9 (1991-92) and Y11R6 (1996-97) in the Hawaii Drosophila Stock Center's records; in the rest of the paper we use the convention of referring to each cross by the $D$. silvestris stock number. These two stocks represent geographically distinct populations that differ in a secondary sexual character, the number of rows of bristles on male foretibiae (Carson et al., 1982). The D. heteroneura stock was the isofemale line W48B6; this is the only line of $D$. heteroneura that is available in captivity, and this species has been seen in the wild only once since 1983 (Boake, unpubl. obs.). It is 
unclear whether an outbred population of either species could be maintained in a flight cage smaller than a gymnasium because these are large territorial flies that require appreciable space and time for rearing, and because sexual selection probably takes place under laboratory conditions (Carson, 1987; Boake, 1989a). Because a generation takes about three months, work on these species is necessarily slower than on smaller species with more rapid developmental times.

We use the convention of referring to $D$. silvestris as $\mathrm{S}$ and $D$. heteroneura as $\mathrm{H}$. Additionally, we list the species of the female parent first; thus hybrids from the cross of $D$. silvestris females with $D$. heteroneura males are called SH individuals, and hybrids of the reciprocal cross are called HS individuals.

Hybrids were produced with two methods. The U26B9 cross, conducted in 1991-92, was produced with matings between small numbers of flies in glass vials (Price \& Boake, 1995); the Y11R6 cross (1996-97) used mass-matings of several dozen flies of each species in large glass jars. Because it is faster to produce SH progeny than to produce HS progeny (Craddock, 1974; Val, 1977; Price \& Boake, 1995), individuals from reciprocal crosses with U26B9 were tested at different times ( $\mathrm{SH}$ in the early spring of 1992; and HS in the late spring of 1992).

\section{Behavioural observations and analyses}

We observed courtship behaviour and aggressive behaviour, considering acts that preceded copulation as well as the duration of copulation under the category of 'courtship.' Individuals were observed once, and all sample sizes refer to the number of individuals. We scored the variables for mating and aggression differently. The acts that precede copulation are very similar for the two species (Spieth, 1981), but pilot studies had suggested differences in timing. Accordingly, we focused on the latencies and durations of various acts. Aggressive postures differ between the two species, as described above, so our data for the studies of aggression were the postures in analogous acts.

Courtship For the U26B9 cross we conducted courtship observations of the $\mathrm{SH}$ and HS hybrids independently. In each case we took data simultaneously from all possible pairs of $\mathrm{S}, \mathrm{H}$, and one type of hybrid (SH or HS). Homotypic pairs were observed at the same time as heterotypic pairs in order to control for day-to-day differences in the probability of mating. In the studies of HS hybrids, $\mathrm{H}$ was under-represented because of overheating in one of our coldrooms. For the Y11R6 cross we observed fewer types of combinations of genotypes; one set of tests was of $\mathrm{S}$ males with all four genotypes of females (H, S, HS and $\mathrm{SH})$ and the other set of tests was of $\mathrm{H}$ females with all four genotypes of males (H, S, HS and $\mathrm{SH}$ ).

Pairs of flies were observed in clear plastic chambers $(13 \times 15 \mathrm{~cm}$ floors, $4.5 \mathrm{~cm}$ high; available commercially as $24 \mathrm{oz}$ deli boxes) which had floors made of blotting paper and which contained a small piece of damp sponge for humidity. As many as 27 chambers were observed simultaneously; the identity of each pair in a chamber was randomized. Flies were at least one month old (and thus sexually mature) at the start of observations. All males were moved into the chambers at least $5 \mathrm{~min}$ before females were put in. Each pair was observed for $1 \mathrm{~h}$ from the time that the female entered the chamber. We recorded the latencies until several landmarks in courtship: male wing vibration (this takes place in a head-under-wings posture, and involves both wings being vibrated simultaneously), the onset of copulation, and the end of copulation.

The most difficult part of the study of genetic differences in mating behaviour arises from mating behaviour being the result of the interactions of two individuals (Fuller \& Hahn, 1976). Both sexes must be evaluated separately and together during the statistical analysis. Here we outline the strategy for our analyses. We used nonparametric tests because not all the data were normally distributed.

We conducted two separate analyses of the courtship data from the U26B9 cross. First, we performed a simple analysis using data only from homotypic pairings, which is the most common pairing in natural populations for the parental species but unlikely for hybrids because of their rarity. Such an analysis assumes that the behaviour shown with a homotypic partner is the only possible kind of behaviour for an individual. The analysis does not allow an examination of whether female discrimination against heterotypic males can be inherited. This analysis is not presented in detail, but is referred to where the results differ from the overall analysis.

Our main analysis of the U26B9 data was more complex. We pooled the data taken from all possible pairings between different genotypes (e.g. SH female with $\mathrm{SH}$ or $\mathrm{H}$ or $\mathrm{S}$ male, $\mathrm{H}$ female with $\mathrm{SH}$ or $\mathrm{H}$ or $\mathrm{S}$ male, $\mathrm{S}$ female with $\mathrm{SH}$ or $\mathrm{H}$ or $\mathrm{S}$ male). In the first stage of the analysis we broke the data sets into 2 by 2 contingency tables in which both sexes of one type of hybrid and one type of parental species were represented ( $\mathrm{S}$ and $\mathrm{SH}, \mathrm{S}$ and $\mathrm{HS}, \mathrm{H}$ and $\mathrm{SH}$; the coldroom failure precluded an analysis 
of $\mathrm{H}$ and $\mathrm{HS}$ ); this allowed an analysis of the significance of an interaction term as well as of the main effects. None of the interactions was significant. In the second stage of the analysis, for each sex and genotype, we asked whether a trait differed significantly according to the genotype of the partner, using log-likelihood tests. We used the sequential Bonferroni technique to adjust for the large number of related tests (Rice, 1989), and found only one case with a significant effect, the duration of copulation of SH females with different genotypes of partners. For later analyses we pooled the data across the different types of partners because even if significant differences are detected, these nevertheless represent aspects of the phenotype of each genotype. Finally, we tested for differences between the two reciprocal hybrids with Wilcoxon tests and pooled data where we did not find significant differences. The pooled $F_{1}$ means were compared to the parental means and hypotheses about inheritance developed.

Many of the tests described above were inappropriate for the Y11R6 data because fewer combinations of flies had been examined. Where possible, we tested for differences that could be attributed to the genotype of the partner or to differences between reciprocal hybrids. For presentation and drawing genetic inferences, the data from the U26B9 and Y11R6 crosses were pooled by giving each cross equal weight rather than weighting for the number of tests.

Aggression We observed aggression with heterotypic pairs, a hybrid male with either an $\mathrm{S}$ or an $\mathrm{H}$ male in both crosses. In the U26B9 cross each pair was observed for $30 \mathrm{~min}$, with as many as 10 pairs being observed simultaneously; in the Y11R6 cross we observed up to 20 pairs for $1 \mathrm{~h}$. We randomized the locations of different types of pairs in the array of observation chambers, using the same kind of chambers as in the courtship tests. Males were tested at least 1 month after eclosion; they were isolated into shell vials with food no later than the afternoon before the morning of behavioural tests. Each male was put into the observation chamber by gently tapping him out of his shell vial. We recorded the aggressive postures that each male exhibited during the observation session. We tested $\mathrm{SH}$ hybrids with $\mathrm{H}$ and $\mathrm{S}$ males on different days in the U26B9 cross, but for all other tests hybrids were tested with both parental species of male on the same day. Not all pairs fought; we collected data from between 10 and 30 interactions per hybrid genotype.
The data describe whether a particular component of the behaviour in a hybrid male resembled one or the other parent, or was intermediate. We described aggressive behaviour with four action patterns that were readily observable (Spieth, 1981). These were the posture during an approach, wing position after the approach, and head position and leg posture in high-intensity interactions. We scored the posture during an approach as crouched or upright, wings as extended laterally one at a time (S-like) or simultaneously (H-like), heads as side-to-side (S-like) or in a frontal shove (H-like), and leg posture in highintensity interactions as being extended (S-like) or crouched (H-like). Some males showed an intermediate pattern or showed both; these were pooled into a 'both' category. Our variables are the proportion of males of each genotype that showed a certain action pattern. We used contingency table analyses to determine whether the genotype of the opponent affected the form of each act, and log-likelihood tests for differences between genotypes.

\section{Results}

\section{The progress of courtship}

Two components of courtship, the latency to wing vibration and the latency to copulate, did not differ significantly between the parental species in either cross, whether the data were taken from samespecies pairs or from all kinds of pairs (Table 1). In all cases, an average of nearly 20 min elapsed from when a female was introduced to a male until wing vibration began. The entire courtship lasted between 22 and $28 \mathrm{~min}$. Not surprisingly, hybrids resembled the parents.

\section{The probability of copulation}

$\mathrm{H}$ females did not mate with $\mathrm{S}$ males in the $1 \mathrm{~h}$ observation period in the U26B9 cross; in the Y11R6 cross, 7\% of such pairings resulted in copulation within $1 \mathrm{~h}$. We defined a trait 'propensity to mate with S males', which has a high value in $\mathrm{S}$ females and is near zero in $\mathrm{H}$ females in 1-h observations. The $\mathrm{SH}$ and $\mathrm{HS}$ hybrid females did not differ in their likelihood of mating with $\mathrm{S}$ males in either cross $\left(\chi_{1}^{2}=2.5, P>0.05\right)$. In the U26B9 cross the combined $F_{1}$ hybrid females had a significantly lower probability than $\mathrm{S}$ females of mating with $\mathrm{S}$ males: 20 of 92 tests with $F_{1}$ hybrid females resulted in copulation whereas 20 of 46 tests with $\mathrm{S}$ females resulted in copulation $\left(\chi_{1}^{2}=7.81, P<0.01\right)$. In the Y11R6 cross, the $F_{1}$ hybrid females mated with $S$ males in $41 \%$ of the tests but $\mathrm{S} \times \mathrm{S}$ pairs had a $31 \%$ 
Table 1 Mating behaviour of Drosophila silvestris and D. heteroneura, together with their $F_{1}$ hybrids. Each value is the mean $( \pm 1 \mathrm{SE})$ of tests with two crosses; the total number of pairs scored is given in parentheses below the means

\begin{tabular}{lccc}
\hline Genotype & $\begin{array}{c}\text { Latency to wing } \\
\text { vibration (min) }\end{array}$ & $\begin{array}{c}\text { Latency to } \\
\text { copulate (min) }\end{array}$ & $\begin{array}{c}\text { Duration of } \\
\text { copulation (min) }\end{array}$ \\
\hline D. silvestris & $20.9 \pm 1.2$ & $26.8 \pm 1.6$ & $12.3 \pm 0.3$ \\
& $(154)$ & $(104)$ & $(103)$ \\
F hybrid & $19.0 \pm 0.8$ & $23.7 \pm 1.1$ & $10.4 \pm 0.2$ \\
& $(263)$ & $(244)$ & $(244)$ \\
D. heteroneura & $18.9 \pm 1.4$ & $22.8 \pm 1.7$ & $7.8 \pm 0.3$ \\
& $(111)$ & $(79)$ & $(79)$ \\
\hline
\end{tabular}

chance of mating ( $n=59$ pairs), and thus the hybrid females were not less likely to mate with $\mathrm{S}$ males. The interpretation of inheritance of the likelihood of mating with $\mathrm{S}$ males thus depends on the nature of the cross. In general, the Y11R6 males have a greater likelihood of mating than the U26B9 males with $\mathrm{H}$ females and both hybrid females (HS and $\mathrm{SH})$.

\section{The duration of copulation}

Copulation duration was not dependent on the type of female except for SH females in the U26B9 cross. In this case the copulation duration of females differed according to the genotype of their partners. For homotypic matings, S pairs (U26B9) had significantly longer copulations than $H$ pairs $(12.3 \pm 0.7 \mathrm{~min}$ vs. $8.8 \pm 1.2 \mathrm{~min}, P=0.006) ;$ Y11R6 pairs had an average copulation duration of $12.3 \pm 0.65 \mathrm{~min}$. For both crosses, differences in copulation duration appear to depend on the male genotype (Price \& Boake, 1995). The reciprocal hybrid males did not differ significantly in the U26B9 cross but SH males had significantly longer copulation durations than HS in the Y11R6 cross $(9.5 \pm 0.3 \mathrm{~min}$ vs. $8.2 \pm 0.4 \mathrm{~min}, P=0.003)$. Thus variation in copulation duration appears to be sexlimited in expression but evidence for sex-linkage is modest. The pattern of inheritance suggests polygenic control.

\section{Aggression}

First we tested whether the form of the action pattern depended on the genotype of the opponent, using chi-squared tests. There was no pattern to the significant differences for the two crosses and there were only a few differences between the crosses involving the U26B9 and Y11R6 D. silvestris flies. In the U26B9 cross, in the initial stage of aggression, S males were more likely to show the 'walk' than the 'crouch' posture when approaching the HS hybrid, and more likely to show both action patterns when approaching the $\mathrm{SH}$ hybrid $(P=0.001$ in each case). Also in U26B9, in high-intensity aggression, the SH hybrids were more likely to show both leg postures when paired with an $\mathrm{H}$ male than when paired with an $\mathrm{S}$ male (log-likelihood test, $P=0.005)$. In the Y11R6 cross, the HS hybrids were more likely to show both wing postures with $\mathrm{S}$ males than with $\mathrm{H}$ males, and $\mathrm{S}$ males were also more likely to show both wing postures in tests with HS males than with SH males $(P=0.004$ and 0.02 , respectively). Apart from this, the reciprocal hybrids did not differ in their patterns of behaviour ( $P>0.05$ in all cases).

For three of the four aggressive action patterns (early posture, early wing extension and escalated legs) the two crosses gave the same result (Table 2). The early posture did not differ between the species as much as some other traits, which may result from the difficulty of scoring this posture. The tendency to show both action patterns may be explained because the first stage of courtship involves male crouching, and males cannot tell males from females (or from jumping spiders; Boake, unpubl. obs.) until they elicit a response from the animal that is being approached (Boake \& Hoikkala, 1995). Hybrid males were very unlikely to crouch during the first stage of aggression, and thus resembled $\mathrm{S}$ males.

For the posture during approach and the posture of the legs during high-intensity fights, the hybrids clearly resembled S (Table 2). All hybrids showed the double-wing extension of $\mathrm{H}$. During escalated aggression, nearly all hybrids showed the extended leg posture that is characteristic of S.

The head posture during escalated aggression differed between U26B9 (59\% S-like) and Y11R6 (100\% S-like). More remarkably, fewer than $7 \%$ of 
Table 2 Behaviour of Drosophila silvestris and D. heteroneura, together with their $\mathrm{F}_{1}$ hybrids, during aggressive interactions, expressed as the percentage of males that showed silvestris-like action patterns. These are means from the two crosses except in the case of the 'escalated head' posture, where major differences were found; results for the U26B9 cross are given first. The total number of males scored is given in parentheses below the means

\begin{tabular}{lcccc}
\hline Species & $\begin{array}{c}\text { Early } \\
\text { posture } \\
\text { \% S-like }\end{array}$ & $\begin{array}{c}\text { Early } \\
\text { wings } \\
\% \text { S-like }\end{array}$ & $\begin{array}{c}\text { Escalated } \\
\text { head } \\
\% \text { S-like }\end{array}$ & $\begin{array}{c}\text { Escalated } \\
\text { legs } \\
\% \text { S-like }\end{array}$ \\
\hline D. silvestris & 85 & 86 & 59,100 & 100 \\
F hybrid & $(91)$ & $(85)$ & $(22,20)$ & $(44)$ \\
D. heteroneura & 78 & 1 & 4,67 & 82 \\
& $(187)$ & $(191)$ & $(46,43)$ & $(96)$ \\
& 24 & 2 & 0,0 & 3 \\
& $(100)$ & $(98)$ & $(14,22)$ & $(40)$ \\
\hline
\end{tabular}

the hybrids of the U26B9 cross showed the S-like head posture whereas $67 \%$ of the hybrids of the Y11R6 cross showed dominance of the $S$ head posture. Thus three of the four aggressive action patterns show consistent patterns of inheritance in the two crosses. For head posture the two crosses suggest dominance of the $\mathrm{H}$-like posture in the U26B9 cross and partial dominance in the Y11R6 cross.

\section{Discussion}

Role of behavioural differences in reproductive isolation

In a previous paper we showed that courtship discrimination between these two species appears to result from whether a pair initiates courtship, rather than from later stages of the interaction (Price \& Boake, 1995). We noted that aggressive behaviour had diverged to such an extent that males of the two species do not fight each other, and hardly ever give aggressive displays, although hybrid males fight both parental species successfully (Price \& Boake, 1995). We also asked whether those aspects of mating behaviour that have diverged are currently relevant to sexual selection within either species (Boake, 1989a; Boake \& Hoikkala, 1995; Hoikkala \& Welbergen, 1995). The two aspects of mating behaviour that differed significantly between the parental species were the probability of copulation with $\mathrm{S}$ males and the duration of copulation (Table 1). The probability of copulation is a major aspect of sexual selection; we need to know the proximate reasons for its variation. Copulation duration could be relevant to sperm transfer and usage; further experiments will be necessary to examine this. We are attempting to identify and experimentally manipulate the aspects of the male phenotype that are important to females. Because aggressive displays are largely used by males to defend territories that are visited by females for mating but that do not contain other resources (Spieth, 1981), the displays are clearly sexually selected. However, it is difficult to hypothesize about the role of aggressive displays in reproductive isolation because the species have diverged to such a great extent.

\section{Inheritance of differences between the species}

Behavioural differences between $D$. silvestris and $D$. heteroneura are under genetic control. Reciprocal hybrids did not differ substantially for any traits, indicating that autosomal genes are involved. Thus although the $\mathrm{X}$ chromosome is a major contributor to differences in head width (Templeton, 1977; Val, 1997), it does not influence differences in aggressive behaviour. In some cases hybrids were very similar to one parent or the other, suggesting simple dominance or a threshold trait with polygenic control. In other cases their behaviour was intermediate, which could be explained by codominance at a single locus or by polygenic inheritance.

We hybridized isofemale lines, and thus we view our Mendelian analyses as providing hypotheses to be tested by examining the behaviour of $F_{2}$ and backcross hybrids. The results from the two crosses were qualitatively the same. Ideally, additional stocks of each species should be crossed, but the increasing rarity of both species in the forest, caused by habitat destruction and the effects of an introduced predator, precludes this possibility. 
Studies of hybrid mating behaviour are more complex than studies of hybrid morphology. Morphology may vary between individuals, but accurate phenotypic values are expected, because repeatabilities are influenced only by measurement error. Studies of hybrid mating behaviour are influenced by two additional levels of variability, which are the inherent variation in an individual's behaviour and the variation caused by behaviour of its partner (Fuller \& Hahn, 1976; Boake, 1989b). In an ideal experiment, every individual would be measured repeatedly, with a variety of partners, and its mean phenotype used in analyses. Given the constraints of time and space in our study, we chose to measure each individual once, and to pair each type of hybrid with several types of partner (members of both parental species and of the hybrid). Our test of whether a trait varied significantly according to the genotype of the partner is a test of behavioural plasticity; in nearly all cases we found no significant plasticity.

The posture during the earliest stage of aggressive behaviour was difficult to score because crouching is a component of courtship in both species, but a component of aggression only in $\mathrm{H}$. As a further complication, $\mathrm{H}$ males were far more likely to show homosexual courtship than S males: $70 \%$ of all observations of $\mathrm{H}$ males with hybrid males included some wing vibration by $\mathrm{H}$, but only $16 \%$ of the observations of $\mathrm{S}$ males included wing vibration. Both hybrids showed as much male-directed wing vibration as $\mathrm{H}$ ( $\mathrm{SH} 62 \%$, $\mathrm{HS} 50 \%$ ). No males differed in the likelihood of wing vibration according to the genotype of the opponent: $\mathrm{S}$ males received as much wing vibration as $\mathrm{H}$ males, but gave considerably less. Thus the tendency to show wing vibration to other males shows dominance of the H-like value. In future, the crouched posture could be scored as aggressive if accompanied by a description of the behaviour subsequent to each crouch.

The parental males were quite distinct for the aggressive traits of early wing posture and escalated leg posture, and the hybrids distinctly resembled one parent or the other. Three components of aggressive behaviour showed clear dominance of one parental species (Table 2): one trait was $\mathrm{H}$-like and two were S-like. The independence of the patterns of dominance of these different components of behaviour may indicate that they are controlled by different genes; however, such a hypothesis must be tested with assessments of the behaviour of backcross and $\mathrm{F}_{2}$ flies.

In the escalated aggressive interactions, the $D$. silvestris males had different frequencies of S-like head positions, with the U26B9 males being more likely to show the $\mathrm{H}$-like posture. The $\mathrm{F}_{1}$ hybrid males showed a far higher tendency to give the S-like posture in the Y11R6 cross. This difference could be caused by a difference between the two stocks or by interobserver differences (scoring the head posture requires very close observation of the fight). Two of us (CB and DA) tested the second hypothesis by observing a small sample of U26B9 males with each other and with $F_{1}$ hybrid males from the Y11R6 cross. Our recent results were consistent with the earlier ones, with $76 \%$ of U26B9 males giving S-like escalated head postures when paired with U26B9, and 55\% giving S-like postures when paired with a hybrid male. We noted that the postures appear to form more of a continuum than a discrete difference, and thus we conclude that the differences between the two crosses could be partly a result of interobserver variation but that a real difference exists between the D. silvestris stocks. The U26B9 and Y11R6 stocks came from populations that differ in the number of rows of tibial hairs on males, with the two-row state being ancestral (Carson et al., 1982). Based on molecular genetic data, it is thought that $D$. heteroneura evolved from $D$. silvestris before the three-row population evolved (DeSalle et al., 1986). The 2-row D. silvestris populations are more closely related to the $D$. heteroneura populations than the 3-row $D$. silvestris populations are related to $D$. heteroneura populations (DeSalle et al., 1986). Thus it is possible that the closer resemblance of the U26B9 aggressive head posture to the posture of $D$. heteroneura is associated with this evolutionary history.

In hybrids between $\mathrm{S}$ and $\mathrm{H}$, the broad head of $\mathrm{H}$ shows a strong influence of genes on the $\mathrm{X}$ chromosome (Templeton, 1977; Val, 1977; Lande, 1981b). Carson \& Templeton (1984) proposed that the difference in head shape was attributable to a coadapted gene complex, and Spieth (1981) proposed that the crouched posture and head-on shove of $\mathrm{H}$ coevolved with the broadened head, although he did not invoke a coadapted gene complex. Our observation that some components of aggressive behaviour show dominance of the $D$. silvestris type, and others show dominance of the $D$. heteroneura type is inconsistent with a coadapted gene complex that controls both head shape and posture. Furthermore, the lack of X-chromosomal linkage of the genes for posture, despite X-chromosomal influences on head shape, is evidence against a coadapted gene complex that controls both posture and head shape and that is linked on the same chromosome. However, coevolution of two traits can occur through epistatic gene 
interaction among unlinked genes (Butlin \& Ritchie, 1989), so Spieth's hypothesis is not invalidated by our failure to find sex-linkage for behavioural traits.

Ideally, a study of hybrid behaviour involves a complete diallel analysis of at least four stocks that is conducted simultaneously (Sokolowski \& Bauer, 1989; Welbergen et al., 1992). However, this approach is not feasible with the large picturewinged flies because of the huge amount of time, space, and labour that is necessary for conducting a single cross. The alternative is to proceed in a stepwise fashion, using homotypic pairs as controls. These species have stimulated the development of several controversial hypotheses, and thus even though the studies progress far slower than with species that are reared more easily, analyses of the divergence between these species is essential for testing the hypotheses.

\section{Nature of genetic control of behavioural differences}

We found that for the duration of copulation the hybrids have intermediate phenotypes and thus the trait could be under polygenic control. In contrast, three aggressive traits showed clear patterns of dominance that were consistent between crosses; this could be a result of a single gene of major effect, or a threshold trait with polygenic control. The difference between courtship and aggression in the mode of inheritance of differences between species may be more apparent than real, resulting from our choice of traits to score. One mating behaviour that may show polygenic inheritance, the probability of copulation with S males, is undoubtedly a summary of many contributing factors. The duration of copulation is probably influenced by fewer factors, and it shows some degree of dominance. The components of aggressive behaviour are each more like ethological action patterns, and each pattern shows discrete differences between the species. Perhaps each aggressive trait is influenced by fewer genes than a summary such as 'aggressive success' would be, and thus such traits could be more likely to show simple dominance.

One of the most contentious issues in current studies of reproductive isolation concerns the number of genes involved, because models of speciation differ as to whether they invoke a few or many genes (Barton \& Charlesworth, 1984; Carson \& Templeton, 1984). We believe that this issue needs to be addressed by examining species with little isolation rather than older species pairs, which would have had time for genetic divergence subsequent to isolation. Our results indicate that in studies of behavioural reproductive isolation, the choice of traits may be critical: 'summary' traits such as mating speed or the probability of copulation, which represent the accumulation of many genetic and environmental factors, are far more likely to show polygenic control than traits that more nearly resemble fixed action patterns and that contribute to the summary traits. Traits that are under polygenic control can be investigated further with statistical analyses (Lande, 1981b) or quantitative trait loci (Paterson et al., 1988; Zeng, 1994) to estimate the number of factors involved, if the behavioural phenotypes are sufficiently distinct. On the other hand, traits that show clear dominance can be subjected to careful linkage analyses (Sokolowski \& Bauer, 1989) to determine whether a few or many loci are influencing them. Thus, instead of the usual analyses of mating probabilities, we advocate a far more detailed analysis of the components of behavioural differences between species, as the more valuable route to understanding behavioural reproductive isolation.

\section{Acknow ledgements}

We are very grateful to C. Boggs, J. Lawson, $\mathrm{S}$. McKee and S. Moore for assistance with rearing the stocks, and to K. Kaneshiro for providing the founders of our stocks. R. Snook, L. Tompkins and an anonymous reviewer gave valuable comments on the manuscript. D.P. was supported by an NIH Ethology training grant at the University of Tennessee. C.B. and D.A. thank NSF grant IBN-9514041 for support.

\section{References}

AHEARN, J. N. AND TEMPLETON, A. R. 1989. Interspecific hybrids of Drosophila heteroneura and D. silvestris. I. Courtship success. Evolution, 43, 347-361.

BARTON, N. H. AND CHARLESWORTH, B. 1984. Genetic revolutions, founder effects, and speciation. Ann. Rev. Ecol. Syst., 15, 133-164.

BOAKE, C. R. B. 1989a. Correlations between courtship success, aggressive success, and body size in a picturewinged fly, Drosophila silvestris. Ethology, 80, 318-329.

BOAKE, C. R. B. 1989b. Repeatability: its role in evolutionary studies of mating behavior. Evol. Ecol., 3, 173-182.

BOAKE, C. R. B. AND HOIKKALA, A. 1995. Courtship behaviour and mating success of wild-caught Drosophila silvestris males. Anim. Behav., 49, 1303-1313.

BUtLIN, R. K. AND RITCHIE, M. G. 1989. Genetic coupling in mate recognition systems: what is the evidence? Biol. J. Linn. Soc., 37, 237-246.

CARson, H. L. 1982. Evolution of Drosophila on the newer Hawaiian volcanoes. Heredity, 48, 3-25. 
CARSON, H. L. 1987. High fitness of heterokaryotypic individuals segregating naturally within a long-standing laboratory population of Drosophila silvestris. Genetics, 116, 415-422.

CARSON, H. L. AND TEMPLETON, A. R. 1984. Genetic revolutions in relation to speciation phenomena: the founding of new populations. Ann. Rev. Ecol. Syst., 15, 97-131.

CARSON, H. L., VAL, F. C., SIMON, C. M. AND ARCHIE, J. W. 1982. Morphometric evidence for incipient speciation in Drosophila silvestris from the island of Hawaii. Evolution, 36, 132-140.

CARSON, H. L., KANESHIRO, K. Y. AND VAL, F. C. 1989. Natural hybridization between the sympatric Hawaiian species Drosophila silvestris and Drosophila heteroneura. Evolution, 43, 190-302.

CHARlesworth, B., LANDE, R. AND Slatkin, M. 1982. A neo-Darwinian commentary on macroevolution. Evolution, 36, 474-498.

CONAnT, P. 1978. Lek Behavior and Ecology of Two Sympatric Homosequential Hawaiian Drosophila: Drosophila heteroneura and Drosophila silvestris. M.Sc. Thesis, University of Hawaii.

COYNE, J. A. 1992. Genetics and speciation. Nature, 355, $511-515$

COYNE, J. A. AND ORR, H. A. 1989. Patterns of speciation in Drosophila. Evolution, 43, 362-381.

CRADDOCK, E. M. 1974. Reproductive relationships between homosequential species of Hawaiian Drosophila. Evolution, 28, 593-606.

DESAlLE, R., GIDDINGS, L. V. AND KANESHIRO, K. Y. 1986. Mitochondrial DNA variability in natural populations of Drosophila. II. Genetic and phylogenetic relationships of natural populations of $D$. silvestris and $D$. heteroneura. Heredity, 56, 87-96.

FRASER, I. AND BOAKE, C. R. B. 1997. Behavioral isolation, test designs, and Kaneshiro's hypothesis. Am. Nat., 149, $527-539$.

FULLER, J. L. AND HAHN, M. E. 1976. Issues in the genetics of social behavior. Behav. Genet., 6, 391-406.

hoikKala, A. AND Welbergen, P. 1995. Signals and responses of females and males in successful and unsuccessful courtships of three Hawaiian lek-mating Drosophila species. Anim. Behav., 50, 177-190.

KANESHIRO, K. Y. 1976. Ethological isolation and phylogeny in the Planitibia subgroup of Hawaiian Drosophila. Evolution, 30, 740-745.

KANESHIRO, K. Y. 1989. The dynamics of sexual selection and founder effects in species formation. In: Giddings,
L. V., Kaneshiro, K. Y. and Anderson, W. W. (eds) Genetics, Speciation, and the Founder Principle, pp. 279-296. Oxford University Press, Oxford.

KANESHIRO, K. Y. AND BOAKE, C. R. B. 1987. Sexual selection and speciation: issues raised by Hawaiian Drosophila. Trends Ecol. Evol., 2, 207-212.

LANDE, R. 1981a. Models of speciation by sexual selection on polygenic traits. Proc. Natl. Acad. Sci. U.S.A., 78, 3721-3725.

LANDE, R. 1981b. The minimum number of genes contributing to quantitative variation between populations. Genetics, 99, 541-553.

PATERSON, A. H., LANDER, E. S., HEWITT, J. D., PETERSON, S. AND TANKSLEY, S. D. 1988. Resolution of quantitative traits into Mendelian factors by using a complete linkage map of restriction fragment length polymorphisms. Nature, 335, 721-726.

PRICE, D. K. AND BOAKE, C. R. B. 1995. Behavioral reproductive isolation in Drosophila silvestris, D. heteroneura, and their $\mathrm{F}_{1}$ hybrids (Diptera: Drosophilidae). J. Insect Behav., 8, 595-616.

RICE, w. R. 1989. Analyzing tables of statistical tests. Evolution, 43, 223-225.

SOKOLOWSKI, M. B. AND BAUER, s. J. 1989. Genetic analyses of pupation distance in Drosophila melanogaster. Heredity, 62, 177-183.

SPIETH, H. T. 1978. Courtship patterns and evolution of the Drosophila adiastola and planitibia species subgroups. Evolution, 32, 435-451.

SPIETH, H. T. 1981. Drosophila heteroneura and Drosophila silvestris: head shapes, behavior and evolution. Evolution, 35, 921-930.

TEMPleton, A. R. 1977. Analysis of head shape differences between two interfertile species of Hawaiian Drosophila. Evolution, 31, 630-641.

TURNER, G. F. AND BURROWS, M. T. 1995. A model of sympatric speciation by sexual selection. Proc. R. Soc. $B, \mathbf{2 6 0}, 287-292$.

VAL, F. C. 1977. Genetic analysis of the morphological differences between two interfertile species of Hawaiian Drosophila. Evolution, 31, 611-629.

WELBERGEN, P., VAN DIJKEN, F. R., SCHARLOO, W. AND KÖHLER, w. 1992. The genetic basis of sexual isolation between Drosophila melanogaster and D. simulans. Evolution, 46, 1385-1398.

ZENG, Z.-B. 1994. Precision mapping of quantitative trait loci. Genetics, 136, 1457-1468. 